\title{
Hybrid lipid-polymer nanoparticles for sustained siRNA delivery and gene silencing
}

\section{Citation}

Shi, Jinjun, Yingjie Xu, Xiaoyang Xu, Xi Zhu, Eric Pridgen, Jun Wu, Alexander R. Votruba, Archana Swami, Bruce R. Zetter, and Omid C. Farokhzad. 2014. "Hybrid Lipid-polymer Nanoparticles for Sustained siRNA Delivery and Gene Silencing." Nanomedicine: Nanotechnology, Biology and Medicine 10 (5) (July): e897-e900. doi:10.1016/j.nano.2014.03.006.

\section{Published Version}

doi:10.1016/j.nano.2014.03.006

\section{Permanent link}

http://nrs.harvard.edu/urn-3:HUL.InstRepos:29058537

\section{Terms of Use}

This article was downloaded from Harvard University's DASH repository, and is made available under the terms and conditions applicable to Open Access Policy Articles, as set forth at http:// nrs.harvard.edu/urn-3:HUL.InstRepos:dash.current.terms-of-use\#OAP

\section{Share Your Story}

The Harvard community has made this article openly available.

Please share how this access benefits you. Submit a story.

\section{Accessibility}




\title{
Hybrid Lipid-Polymer Nanoparticles for Sustained siRNA Delivery and Gene Silencing
}

\author{
Jinjun Shi, PhD ${ }^{a}, 1,{ }^{\star}$, Yingjie Xu, PhD ${ }^{b, 1}$, Xiaoyang Xu, PhDa, Xi Zhu, BS ${ }^{a, d}$, Eric Pridgen, \\ $\mathbf{P h D}^{\mathrm{c}}$, Jun Wu, PhD ${ }^{\mathrm{a}}$, Alexander R. Votruba, BS ${ }^{\mathrm{a}}$, Swami Archana, PhD ${ }^{\mathrm{a}}$, Bruce R. Zetter,

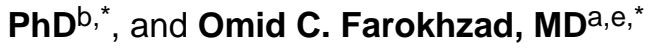 \\ aLaboratory of Nanomedicine and Biomaterials, Department of Anesthesiology, Brigham and \\ Women's Hospital, Harvard Medical School, Boston, MA 02115, USA \\ bVascular Biology Program, Children's Hospital Boston, Harvard Medical School, Boston, MA \\ 02115, USA \\ 'Department of Chemical Engineering, Massachusetts Institute of Technology, Cambridge, MA \\ 02139, USA
}

dKey Laboratory of Drug Targeting and Drug Delivery System, West China School of Pharmacy, Sichuan University, Chengdu 610041, China

eKing Abdulaziz University, Jeddah 21589, Saudi Arabia

\begin{abstract}
The development of controlled-release nanoparticle (NP) technologies has great potential to further improve the therapeutic efficacy of RNA interference (RNAi), by prolonging the release of small interfering RNA (siRNA) for sustained, long-term gene silencing. Herein, we present a NP platform with sustained siRNA-release properties, which can be self-assembled using biodegradable and biocompatible polymers and lipids. The hybrid lipid-polymer NPs showed excellent silencing efficacy, and the temporal release of siRNA from the NPs continued for over one month. When tested on luciferase-expressed HeLa cells and A549 lung carcinoma cells after short-term transfection, the siRNA NPs showed greater sustained silencing activity than lipofectamine 2000-siRNA complexes. More importantly, the NP-mediated sustained silencing of prohibitin 1 (PHB1) generates more effective tumor cell growth inhibition in vitro and in vivo than the lipofectamine complexes. We expect that this sustained-release siRNA NP platform could be of interest in both fundamental biological studies and clinical applications.
\end{abstract}

\footnotetext{
(c) 2014 Elsevier Inc. All rights reserved.

*Corresponding authors: jinjun.shi@zeus.bwh.harvard.edu (J. Shi), bruce.zetter@childrens.harvard.edu (B. R. Zetter), ofarokhzad@zeus.bwh.harvard.edu (O.C. Farokhzad).

${ }^{1}$ These authors contributed equally to the manuscript

Publisher's Disclaimer: This is a PDF file of an unedited manuscript that has been accepted for publication. As a service to our customers we are providing this early version of the manuscript. The manuscript will undergo copyediting, typesetting, and review of the resulting proof before it is published in its final citable form. Please note that during the production process errors may be discovered which could affect the content, and all legal disclaimers that apply to the journal pertain.

Conflicts of interest: O.C.F. has financial interest in BIND Therapeutics, Selecta Biosciences, and Blend Therapeutics, three biotechnology companies developing nanoparticle technologies for medical applications.
} 


\section{Keywords}

lipid-polymer nanoparticle; siRNA; sustained release; gene silencing; cancer

\section{Background}

RNA interference (RNAi) has shown great potential to treat various diseases including cancer, through selectively silencing target genes. ${ }^{1,2}$ To facilitate safe and effective delivery of RNAi therapeutics (e.g., siRNA) to tumor cells - a major hurdle for the clinical applications of RNAi, a few cationic lipid-/polymer-based nanoparticle (NP) platforms have been successfully developed and moved into clinical studies in cancer patients. ${ }^{3-6}$ These NP systems, however, lack sustained siRNA release properties, and their therapeutic efficacy may be limited by transient gene silencing. We hypothesize that sustained siRNA delivery could lead to long-term, effective knockdown of target genes, thus avoiding frequent administration of therapeutic siRNAs to maintain the silencing action and minimizing systemic side effects.

Macroscopic biomaterial scaffolds and microspheres have been demonstrated with sustained siRNA release and prolonged gene silencing, but these strategies are mainly limited to local delivery applications due to their large size. ${ }^{7,8}$ Therefore, the development of controlledrelease NP platforms would be necessary to achieve sustained siRNA delivery for systemic cancer treatment. ${ }^{9,10}$ We have recently developed an innovative lipid-polymer hybrid NP platform for siRNA delivery, ${ }^{11}$ and herein demonstrate that our ameliorated hybrid NPs can release siRNA continuously for periods longer than one month and achieve sustained gene silencing for at least two weeks. The growth of tumor cells treated with our NPs containing siRNA specifically targeting prohibitin 1 (siPHB1) was drastically inhibited both in vitro and in vivo.

\section{Methods}

Hybrid lipid-polymer NPs were prepared by a modified double-emulsion solvent evaporation technique and self-assembly method. ${ }^{11}$ In this work, a new cationic lipid-like compound $\left(\mathrm{G} 0-\mathrm{C}_{14}\right)$ was synthesized by reacting 1,2-epoxytetradecane with PAMAM dendrimer (generation 0), and used for siRNA NP formulation. The siRNA release profile was obtained by measuring the dye-labeled siRNA remaining in the NPs or lipofectamine 2000 (Lipo2K) at different time points. Luciferase expression change was measured in luciferase-expressing $\mathrm{HeLa}$ (Luc-HeLa) cells transfected with NP(siLuc) or Lipo2K(siLuc) for 6 hours. Similarly, the expression level of PHB1 in A549 lung cancer cells was tested by immunoblotting over a period of 14-24 days, after treatment with NP(siPHB1). In vitro A549 cell proliferation was monitored by AlamarBlue assay for 12 days. The A549 xenograft tumor growth was studied using 6-week-old BALB/C nude mice. A detailed description of the methods and experiments is included in the Supplementary Materials. 


\section{Results}

The hybrid lipid-polymer NPs (Figure 1) are composed of an aqueous siRNA core stabilized by the positively charged lipid-like compound $\mathrm{G}_{0}-\mathrm{C}_{14}$, a middle hydrophobic PLGA polymer shell, and a relatively neutral-charge lipid-PEG surface layer. With the use of G0$\mathrm{C}_{14}$ and selected formulation parameters, these NPs can have a sustained siRNA release for more than one month (Figure 2A). The siRNA half-release time can be extended to $\sim 9$ days, as compared to $\sim 8$ hours for Lipo $2 \mathrm{~K}$. To evaluate the silencing efficacy of these sustainedrelease NPs, we introduced NP(siLuc) or Lipo2K(siLuc) into Luc-HeLa cells and measured luciferase expression at different time points. As shown in Figures 2B and S1, the luciferase signal was significantly decreased to less than $10 \%$ at day 2 by both NP(siLuc) and Lipo2K(siLuc). Notably, by day 4, the luciferase signal remained less than $10 \%$ in NP(siLuc)-treated cells, while it recovered to over 30\% in Lipo2K(siLuc)-transfected cells. This result suggested that the sustained siRNA release from NPs could contribute to the prolonged silencing activity. As the Luc-HeLa cells proliferate rapidly (Figure S2), the internalized NPs can be highly diluted with time. This resulted in the recovery of luciferase expression back to $\sim 30 \%$ and $60 \%$ at day 7 and 10, respectively, although still much lower than those ( 68\% and 92\%) in Lipo2K(siLuc)-transfected cells.

In addition to luciferase silencing, we also evaluated the sustained knockdown of PHB1, a protein involved in cell proliferation, apoptosis, chemoresistance, and other biological process. ${ }^{12-14}$ Figure 3A shows that after single transfection with Lipo2K(siPHB1) for 6 hours, the PHB1 expression in A549 cells can be effectively silenced after 3 days. However, it recovered after 14 days. In contrast, the impressive PHB1 silencing was maintained by NP(siPHB1) over 2 weeks, and PHB1 expression was recovered at 24 days (Figure S3). No significant difference was observed in the cellular uptake of siRNA with either the NP or Lipo2K formulation after 6-hour incubation (Figure S4). This result further suggested that the prolonged silencing effect of NPs is more likely due to the sustained siRNA releasing.

To determine whether the sustained silencing could lead to better efficacy in inhibiting cancer cell growth, we first studied the in vitro proliferation of A549 cells after transfection with NP(siPHB1) or Lipo2K(siPHB1). Cell number was measured using AlamarBlue assay, which allows continuously monitoring of cell number in real time. Figure $3 \mathrm{~B}$ demonstrates that the A549 cell growth in the control group is very rapid with a 50-fold increase of cell number on day 9 relative to day 0 , much faster than that in the Lipo2K(siPHB1) and NP(siPHB1) groups. More impressively, the cell proliferation was significantly inhibited after a week in the NP(siPHB1) group, whereas the Lipo2K(siPHB1) group showed continuous cell growth. This means that sustained silencing of PHB1 inhibits A549 cell growth in vitro more efficiently than short-term silencing. Furthermore, we studied in vivo growth of A549 cells using a xenograft mouse model. Consistent with our in vitro results, the mean tumor volumes of NP(siPHB1) group were significantly smaller compared to Lipo2K(siPHB1) or to the two control groups (saline and control NP), as shown in Figure 4. 


\section{Discussion}

Controlled-release polymer technologies have benefited many branches of medicine over the past four decades, as they can enhance the in vivo therapeutic efficacy, reduce the administration frequency, and maximize the patient compliance. ${ }^{15}$ Recently, we have developed self-assembled polymeric NP technologies with sustained-release and targeting properties, which were brought from conception to clinical studies for cancer treatment and smoking cessation. ${ }^{16-18}$ The hybrid lipid-polymer NPs are designed based upon these polymeric nanotechnologies, and combine the unique properties of lipoplexes. It is noteworthy that majority of reported siRNA NP platforms, including those in clinical studies, do not have the sustained siRNA release property. While more tests (e.g., release kinetics effect and systemic delivery) will be needed to clarify the potential of this NP system for further improvement of RNAi therapy, the present results are promising and have demonstrated its capability for sustained, long-term gene silencing and effective inhibition of tumor cell growth. Furthermore, we postulate that the anti-tumor efficacy of our RNAi NPs could be greatly enhanced by incorporating tumor-specific targeting ligands, and/or by simultaneously delivering synergistic siRNA combinations against multiple pathways or drug-siRNA combinations. ${ }^{3,6,19,20}$

\section{Supplementary Material}

Refer to Web version on PubMed Central for supplementary material.

\section{Acknowledgments}

Sources of support: This work was supported by NIH grants R00CA160350 (J.S.), EB015419 (O.C.F.), U54CA151884 (O.C.F.) and R01CA37393 (B.R.Z.), by the David Koch-Prostate Cancer Foundation Program in Nanotherapeutics (O.C.F.), Movember-PCF Challenge Award (O.C.F. and J.S.) and PCF Young Investigator Award (J.S.), and by the National Research Foundation of Korea K1A1A2048701 (O.C.F.).

\section{References}

1. Whitehead KA, Langer R, Anderson DG. Knocking down barriers: advances in siRNA delivery. Nat Rev Drug Discov. 2009; 8:129-138. [PubMed: 19180106]

2. Pecot CV, Calin GA, Coleman RL, Lopez-Berestein G, Sood AK. RNA interference in the clinic: challenges and future directions. Nat Rev Cancer. 2011; 11:59-67. [PubMed: 21160526]

3. Davis ME, Zuckerman JE, Choi CH, Seligson D, Tolcher A, Alabi CA, Yen Y, Heidel JD, Ribas A. Evidence of RNAi in humans from systemically administered siRNA via targeted nanoparticles. Nature. 2010; 464:1067-1070. [PubMed: 20305636]

4. Burnett JC, Rossi JJ, Tiemann K. Current progress of siRNA/shRNA therapeutics in clinical trials. Biotechnol J. 2011; 6:1130-1146. [PubMed: 21744502]

5. Strumberg D, Schultheis B, Traugott U, Vank C, Santel A, Keil O, Giese K, Kaufmann J, Drevs J. Phase I clinical development of Atu027, a siRNA formulation targeting PKN3 in patients with advanced solid tumors. Int J Clin Pharmacol Ther. 2012; 50:76-78. [PubMed: 22192654]

6. Tabernero J, Shapiro GI, et al. First-in-humans trial of an RNA interference therapeutic targeting VEGF and KSP in cancer patients with liver involvement. Cancer Discov. 2013; 3:406-417. [PubMed: 23358650]

7. Krebs MD, Alsberg E. Localized, targeted, and sustained siRNA delivery. Chem Eur J. 2011; 17:3054-3062. [PubMed: 21341332]

8. Nelson CE, Gupta MK, Adolph EJ, Shannon JM, Guelcher SA, Duvall CL. Sustained local delivery of siRNA from an injectable scaffold. Biomaterials. 2012; 33:1154-1161. [PubMed: 22061489] 
9. Xue HY, Wong HL. Tailoring nanostructured solid-lipid carriers for time-controlled intracellular siRNA kinetics to sustain RNAi-mediated chemosensitization. Biomaterials. 2011; 32:2662-2672. [PubMed: 21236485]

10. Ishikawa H, Nakamura Y, Jo J, Tabata Y. Gelatin nanospheres incorporating siRNA for controlled intracellular release. Biomaterials. 2012; 33:9097-9104. [PubMed: 22985993]

11. Shi J, Xiao Z, Votruba AR, Vilos C, Farokhzad OC. Differentially charged hollow core/shell lipidpolymer-lipid hybrid nanoparticles for small interfering RNA delivery. Angew Chem Int Ed Engl. 2011; 50:7027-7031. [PubMed: 21698724]

12. Sievers C, Billig G, Gottschalk K, Rudel T. Prohibitins are required for cancer cell proliferation and adhesion. PLoS One. 2010; 5:e12735. [PubMed: 20856874]

13. Theiss AL, Sitaraman SV. The role and therapeutic potential of prohibitin in disease. Biochim Biophys Acta. 2011; 1813:1137-1143. [PubMed: 21296110]

14. Patel N, Chatterjee SK, Vrbanac V, Chung I, Mu CJ, Olsen RR, Waghorne C, Zetter BR. Rescue of paclitaxel sensitivity by repression of Prohibitin1 in drug-resistant cancer cells. Proc Natl Acad Sci U S A. 2010; 107:2503-2508. [PubMed: 20133800]

15. Farokhzad OC, Langer R. Nanomedicine: developing smarter therapeutic and diagnostic modalities. Adv Drug Deliv Rev. 2006; 58:1456-1459. [PubMed: 17070960]

16. Hrkach J, Von Hoff D, et al. Preclinical development and clinical translation of a PSMA-targeted docetaxel nanoparticle with a differentiated pharmacological profile. Sci Transl Med. 2012; 4:128ra39.

17. Shi J, Xiao Z, Kamaly N, Farokhzad OC. Self-assembled targeted nanoparticles: evolution of technologies and bench to bedside translation. Acc Chem Res. 2011; 44:1123-1134. [PubMed: 21692448]

18. Kamaly N, Xiao Z, Valencia PM, Radovic-Moreno AF, Farokhzad OC. Targeted polymeric therapeutic nanoparticles: design, development and clinical translation. Chem Soc Rev. 2012; 41:2971-3010. [PubMed: 22388185]

19. Creixell M, Peppas NA. Co-delivery of siRNA and therapeutic agents using nanocarriers to overcome cancer resistance. Nano Today. 2012; 7:367-379.

20. Hu CM, Zhang L. Nanoparticle-based combination therapy toward overcoming drug resistance in cancer. Biochem Pharmacol. 2012; 83:1104-1111. [PubMed: 22285912] 

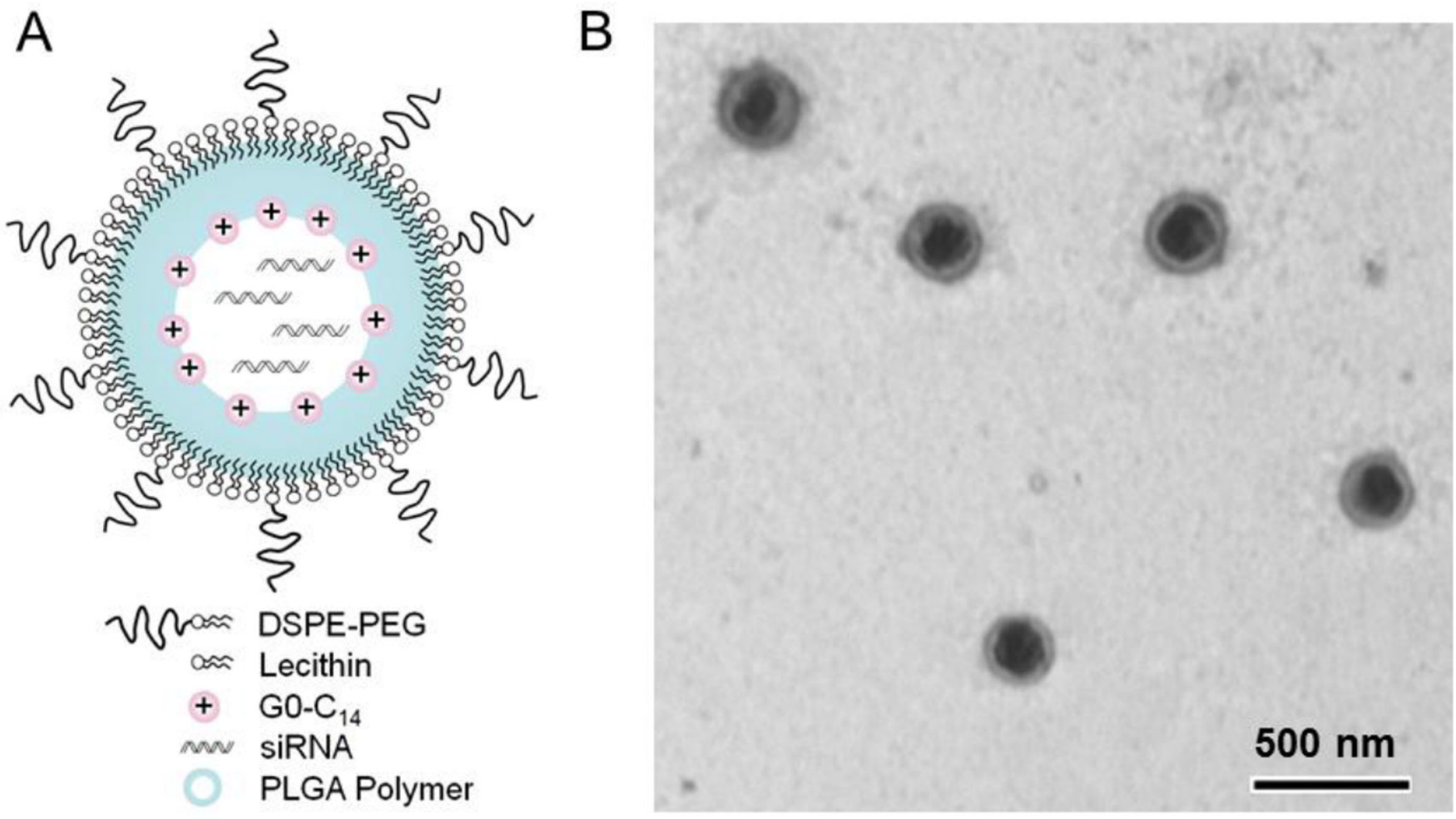

Figure 1.

Hybrid lipid-polymer NPs for siRNA delivery. (A) Schematic and (B) TEM image of the NPs. 

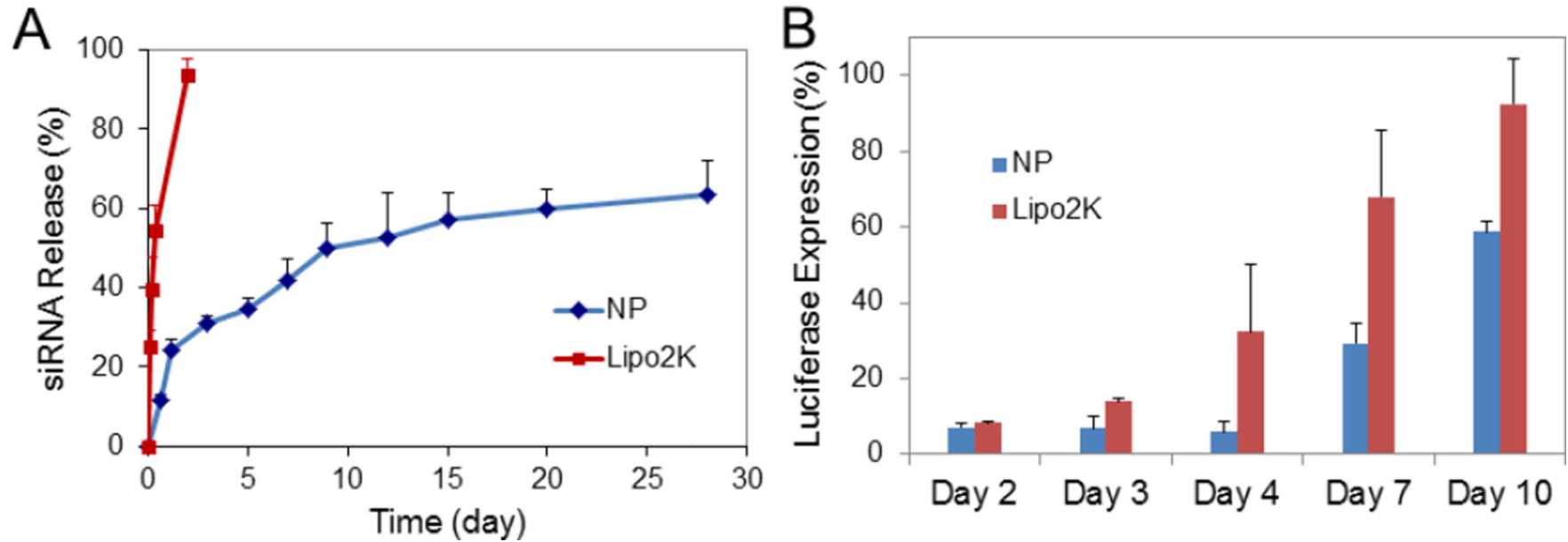

Figure 2.

Sustained siRNA release and luciferase silencing. (A) In vitro siRNA release profiles of the NPs vs. Lipo2K complexes. (B) Luciferase expression vs. time after 6-hour transfection with NP(siLuc) and Lipo2K(siLuc). 
A
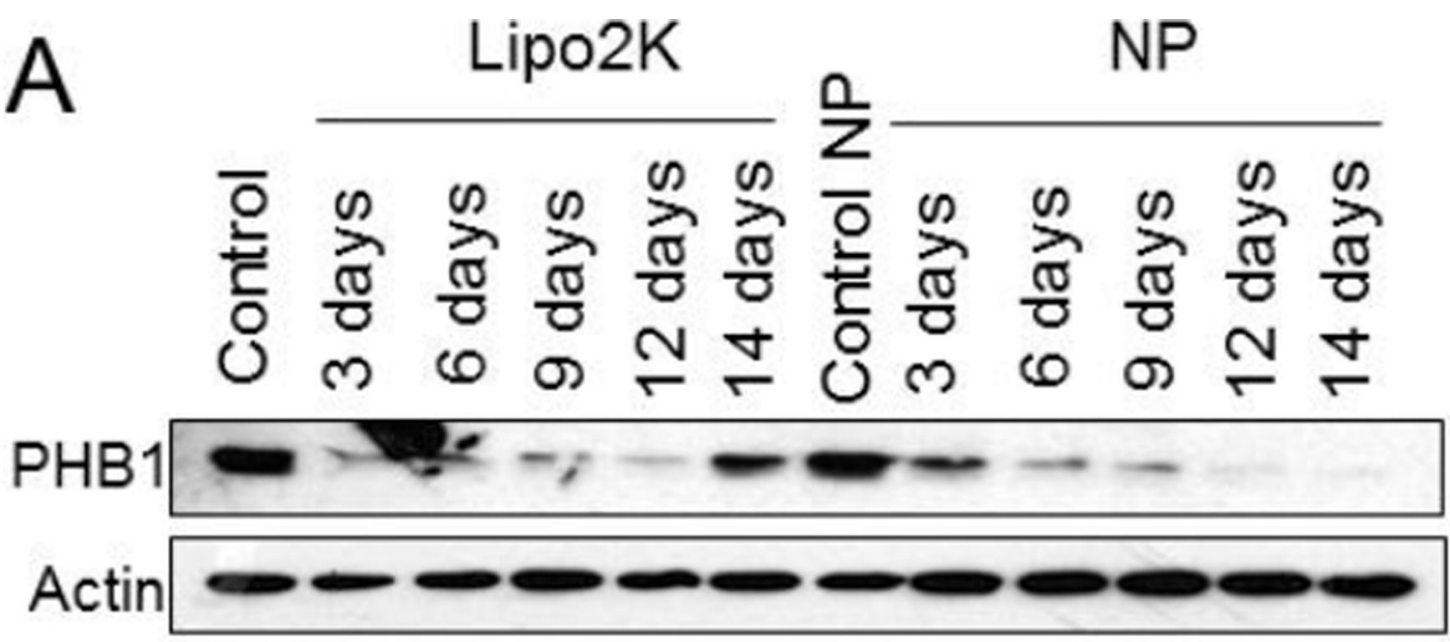

B

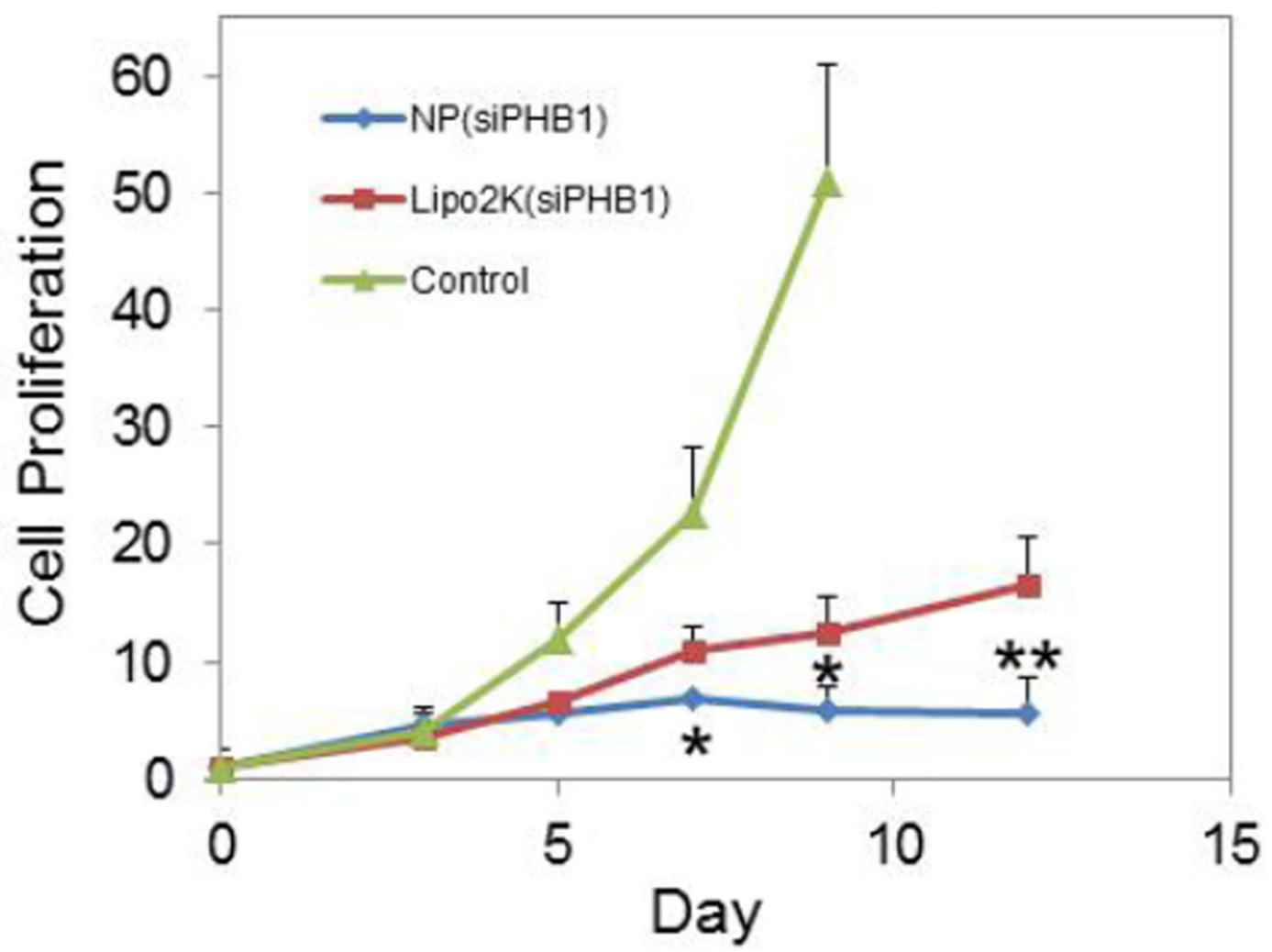

Figure 3.

Sustained PHB1 silencing and its effect on A549 cell proliferation. (A) The PHB1 expression change in A549 cells was measured by Western blot analysis after 6-h transfection. Actin was used as an internal standard. (B) A549 cell proliferation vs. time after transfection. $* \mathrm{P}<0.05, * * \mathrm{P}<0.01, \mathrm{NP} v s$. Lipo2K. 


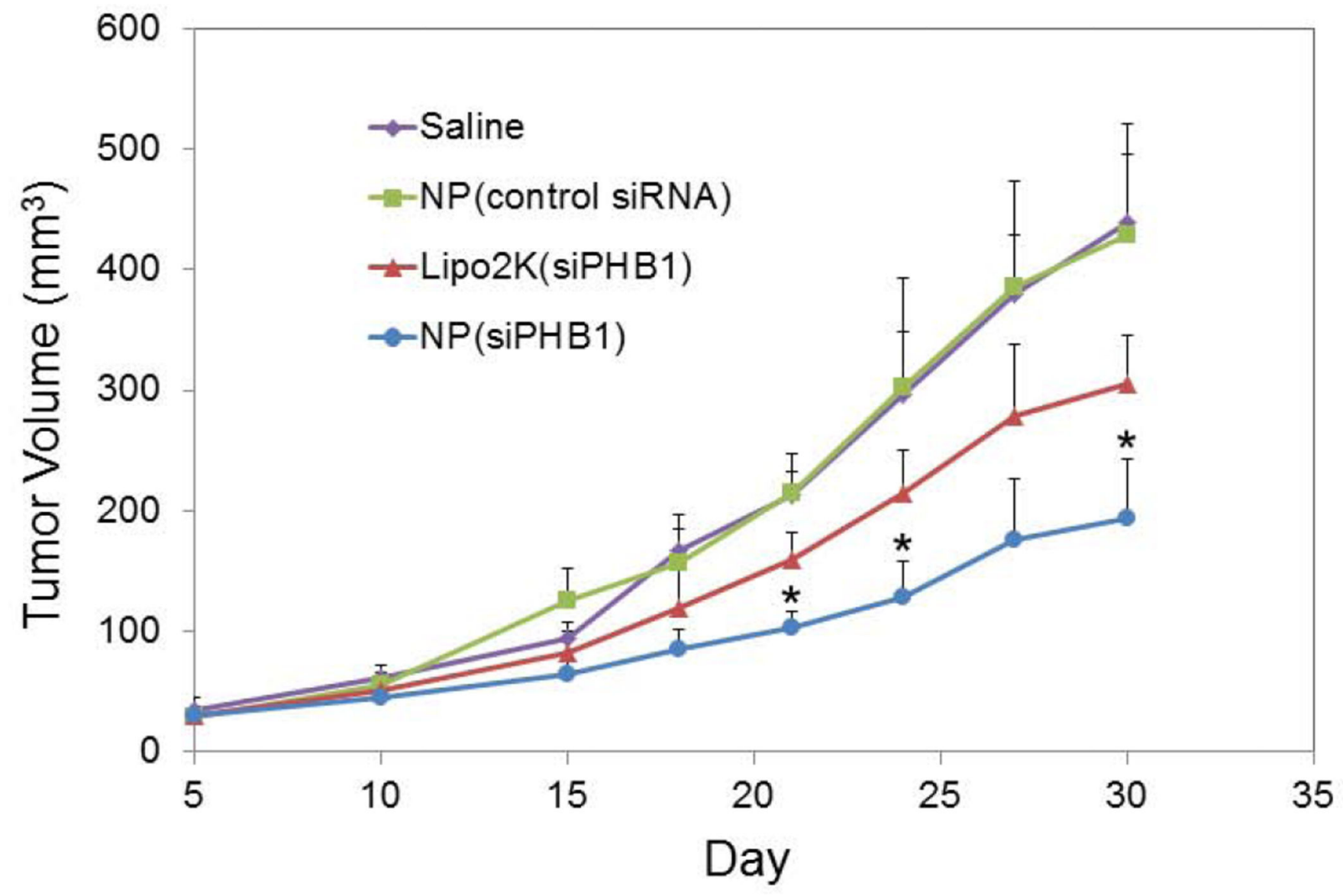

Figure 4.

Xenograft tumor growth of A549 cells pre-treated with NP(siPHB1) vs. Lipo2K(siPHB1), saline, and control NP $(\mathrm{n}=4-5)$. ${ }^{*} \mathrm{P}<0.05, \mathrm{NP} v s$. Lipo2K. 